\title{
Tensile Deformation of Vapor-Deposited Copper Reinforced With Tungsten Wires
}

\author{
William D. Jenkins, * William A. Willard, and Donald E. Harne \\ Institute for Materials Research, National Bureau of Standards, Washington, D.C. 20234
}

(July 29, 1970)

\begin{abstract}
Short-time tensile tests were made at room temperature on sheet specimens of vapor-deposited copper containing zero to 26 volume percent continuous tungsten wires having diameters of 0.0005 , 0.001 , and 0.005 -inch. Specimens were annealed at 25,300 , and $600{ }^{\circ} \mathrm{C}(298,573$, and $873 \mathrm{~K})$ prior to testing. Strength, ductility, shape of the stress-strain curves, and types of fractures were influenced by volume fraction and number of layers of wires as well as by wire diameter and alinement. Strength values for the composites with 2 to 3 percent volume fractions of wires exceeded those predicted by the law of mixtures whereas at higher volume fractions, either conformance to the law was observed or lower values than those predicted were obtained. Increase in strength was accompanied by a decrease in electrical conductivity. All the properties investigated were markedly affected by increasing the annealing temperature. Tungsten wires failed in a ductile manner after considerable localized deformation ("necking") in various sections of the wires.
\end{abstract}

Key words: Composites; copper; electrical conductivity; fracture; law of mixtures; metallic bonding; tensile properties; tungsten; vapor-deposition; wires.

\section{Introduction}

The possibility of producing structural materials having mechanical properties better than those currently available has led to a number of investigations involving metal-fiber composites. However, clarification of basic principles associated with composite behavior can be made only after an accumulation of a significant amount of data obtained in carefully controlled tests and with composites in which the matrix and fibers are mutually compatible. One such composite is a system containing a copper matrix with tungsten wires. $\mathrm{Cu}-\mathrm{W}$ composites were used, in part, by Kelly and Davies [1] ${ }^{1}$ in deriving some basic principles of fiber-reinforcement. Several other investigators have also made mechanical property and electrical resistivity measurements on this composite $[2,3,4,5,6]$. Their materials were made by liquid infiltration or by electroforming processes. Data in the present investigation were obtained from specimens made from vapor-deposited copper and vapor-deposited copper containing tungsten wires. The purposes of this investigation were to: (1) determine the effects of volume fraction, diameter, and number of layers of wires and wire alinement on room-temperature mechanical properties; (2) determine the effect of annealing on these properties; (3) relate mechanical behavior to the shape of the stress-strain curve; (4) ascertain con-

\footnotetext{
${ }^{*}$ Present address: 1829 Ingleside Terrace N.W. Washington, D.C. 20010.
}

${ }^{1}$ Figures in brackets indicate the literature references at the end of this paper. formance of the data to the "law of mixtures"; (5) correlate strength values with electrical conductivity; (6) observe the types of fractures obtained; and (7) determine the mechanism by which the tungsten wires deformed or fractured.

\section{Materials and Testing Procedures}

Sheets of vapor-deposited copper and vapordeposited copper containing tungsten wires were prepared and supplied in the condition as vapordeposited (referred to hereafter also as "VD" or "as annealed at $25^{\circ} \mathrm{C}$ "). The copper sheets were approximately 15 inches $(38.1 \mathrm{~cm})$ long, 1 in $(2.54 \mathrm{~cm})$ wide and 0.01 in $(0.0254 \mathrm{~cm})$ thick. The composite sheets contained continuous tungsten wires. The length and width of these sheets were the same as those for the copper; however, the thickness was dependent on the number of layers of wires $(1,2$, or 3$)$, volume fraction of wires (ranging from 2.1 to $26 \%$ ), and wire diameters $(0.0005,0.001$ or $0.005 \mathrm{in})(0.0127,0.0254$, or $0.127 \mathrm{~mm})$, as shown in table 1 . With one exception, the wires were alined in the longitudinal direction. In the exception, the wires were deliberately misalined in order to ascertain the effects of misalinement on mechanical properties. Blanks 4.25 in $(10.8 \mathrm{~cm})$ long and 1 in $(2.54 \mathrm{~cm})$ wide were cut from the sheets. The blanks were then cut in half in the longitudinal direction to make duplicate adjacent specimens having dimensions of 4.25 by 0.5 in $(10.8$ by $1.27 \mathrm{~cm})$. These were machined into tensile specimens, each having a 0.2 -in 
$(0.51 \mathrm{~cm})$ width over a 1 -in $(2.54 \mathrm{~cm})$ gage length. The pairs of specimens were then divided into three groups: one group to be tested in the vapor-deposited condition, the second group was annealed in vacuum for $15 \mathrm{~min}$ at $300{ }^{\circ} \mathrm{C}$, and the third group was annealed in vacuum for $15 \mathrm{~min}$ at $600{ }^{\circ} \mathrm{C}$. Cross sections of the vapordeposited copper before and after annealing at $600{ }^{\circ} \mathrm{C}$ are shown in figure 1 . Microstructures of some of the
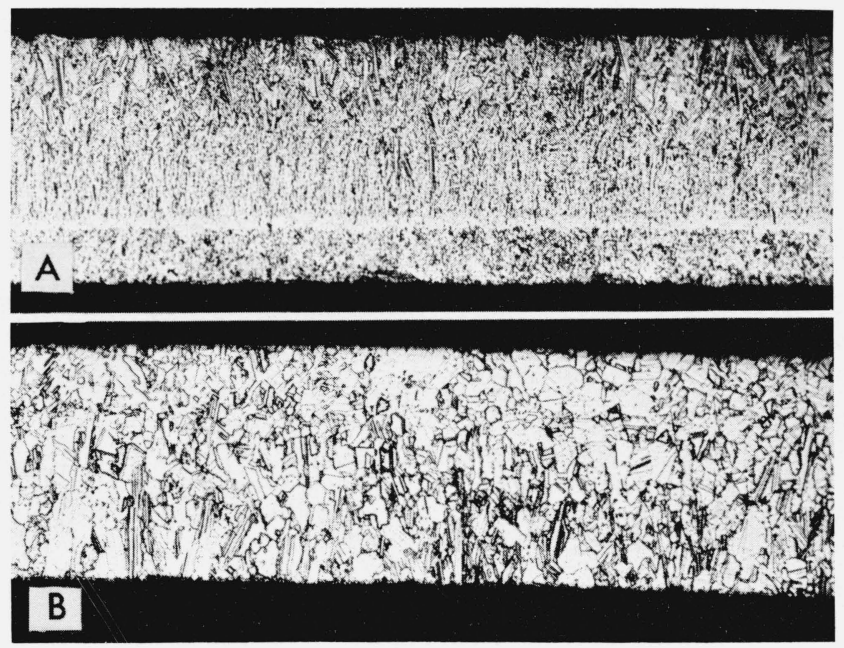

FigURE 1. Microstructure of vapor-deposited copper.

Cross sections, etched in equal parts $\mathrm{NH}_{4} \mathrm{OH}$ and $\mathrm{H}_{2} \mathrm{O}_{2}(3 \%) ; \times 100$.

A. As vapor-deposited (annealed at $25^{\circ} \mathrm{C}$

B. Annealed at $600{ }^{\circ} \mathrm{C}$

as received composites are shown in figure 2. Fairly evenly spaced tungsten wires in the copper matrix are evident in figure 2A, B, and C. Poorly spaced wires are shown in figure 2D for a composite which was examined but not tested. The absence of any observable (at $\times 500$ magnification) chemical reactions at the $\mathrm{Cu}-\mathrm{W}$ interface is shown in figure $2 \mathrm{E}$. Composite sheets having large voids such as those shown in figure $3 \mathrm{~A}$ were also discarded prior to making the tensile specimens, while those having structures as shown in figure $3 \mathrm{~B}, \mathrm{C}$, and $\mathrm{D}$ were considered to be usable. Reactions of the etchant with the interface material were more apparent in the annealed material (fig. 3C and D) than in the material in the condition as vapor-deposited (fig. 3A). Moreover, well-defined grains, evident in the annealed copper (fig. 1B) were not observed in the annealed composite (fig. 3D).

FIGURE 2. Microstructures of vapor-deposited copper with tungsten wires. Cross sections.

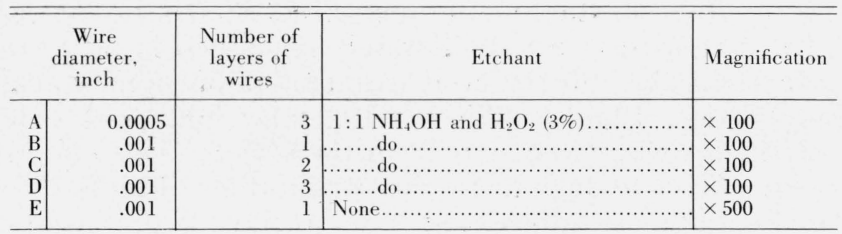
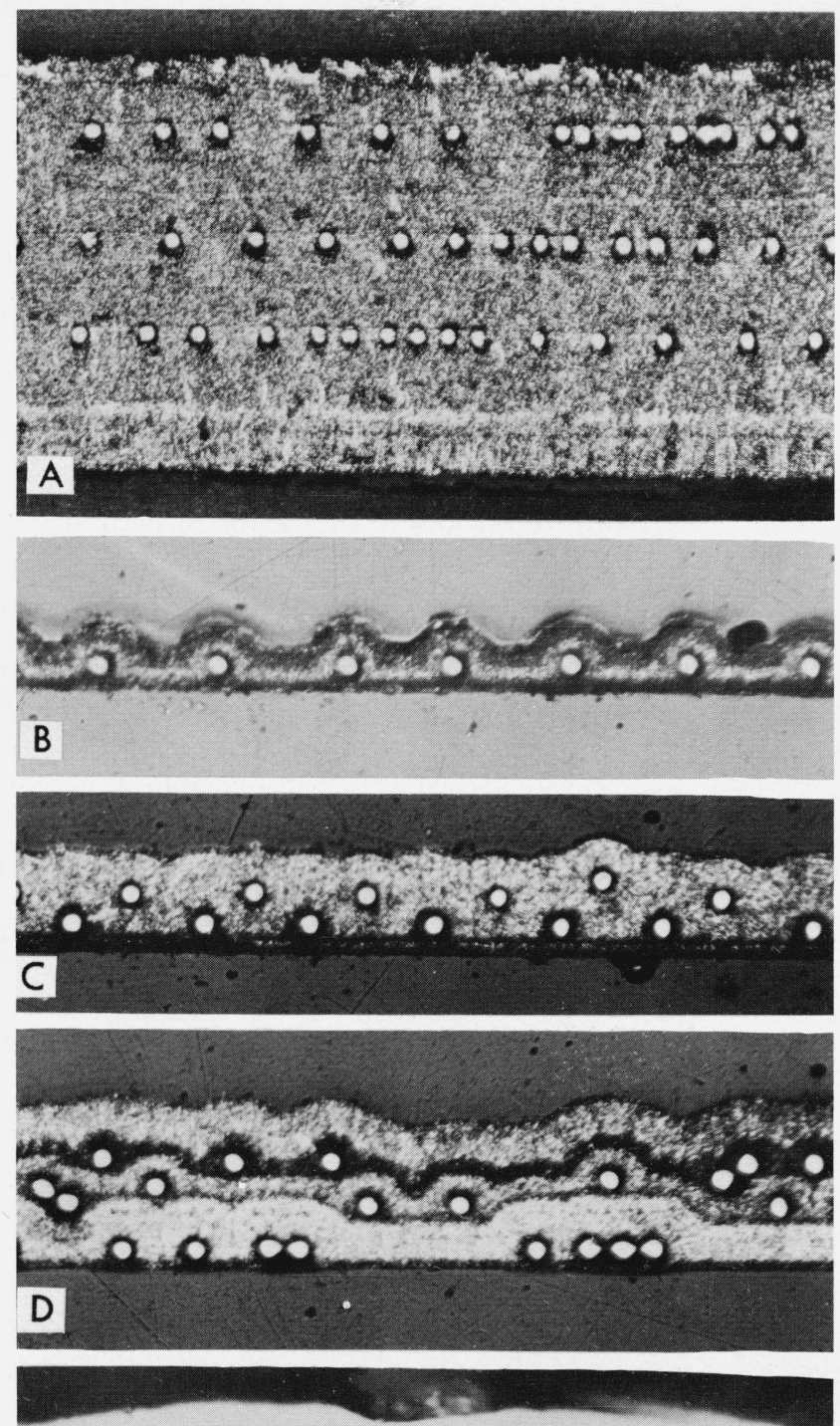

E

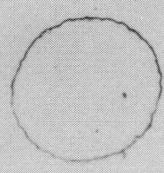


The specimens were tested in tension in air at a temperature of about $25{ }^{\circ} \mathrm{C}$. The movement of the cross-head of the hydraulic machine was controlled to produce a rate of straining of about 0.1 percent per minute. A fixture was specially designed and built in

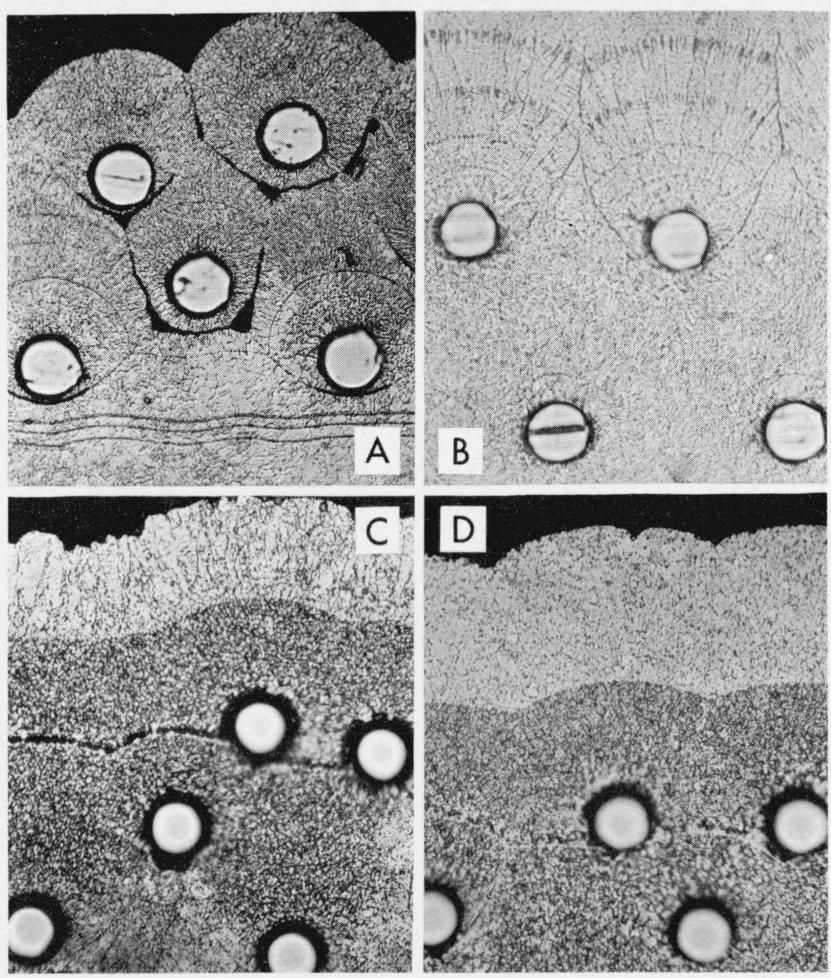

FiguRE 3. Microstructures of vapor-deposited copper with tungsten wires.

Cross sections, etched in equal parts $\mathrm{NH}_{4} \mathrm{OH}^{\circ}$ and $\mathrm{H}_{2} \mathrm{O}_{2}(3 \%): \times 250$.
A, B. - Annealed at $25^{\circ} \mathrm{C}$.
C.. - Annealed at $3000^{\circ} \mathrm{C}$.
D. - Annealed at $600{ }^{\circ} \mathrm{C}$.

this laboratory to insure alinement and nonbending of the specimens as they were placed in the grips (fig. 4A). The same view with fixture removed and specimen ready for testing is shown in figure $4 \mathrm{~B}$.

\section{Results and Discussion}

Test results are shown in Tables 1 and 2 and in figures 5 through 18. The effects of annealing on the stress-extension curves and on the mechanical properties of the copper are shown in figures 5 and 6 . Annealing the copper at $300{ }^{\circ} \mathrm{C}$ had little or no effect on the stress-extension curves from zero to $15 \mathrm{ksi}$ $\left(103.4 \mathrm{Mn} / \mathrm{m}^{2}\right)$. However, the tensile strength of the vapor-deposited copper and the annealed (at $300{ }^{\circ} \mathrm{C}$ ) copper was approximately the same. This occurred in spite of the fact that the yield strength of the annealed specimen was much lower than that of the vapordeposited specimen. Increasing the annealing temperature to $600{ }^{\circ} \mathrm{C}$ caused a greater decrease in yield than in tensile strength. This decrease in strength was accompanied by a large increase in elongation.

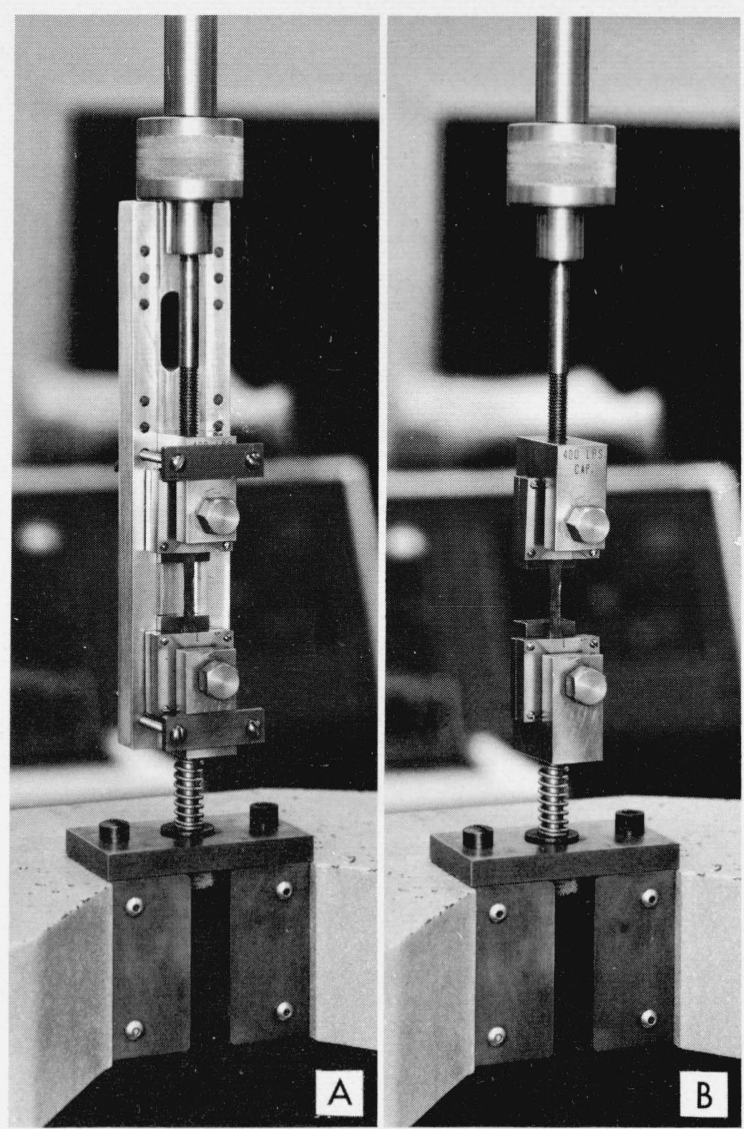

FigUre 4. Photographs of part of the apparatus used for making tension tests on the $\mathrm{Cu}-\mathrm{W}$ composite specimens.

A. Set-up with specially designed fixture for insuring alinement and nonbending of specimen during placement of specimen in grips.

B. Same view as A with fixture removed.

McDanels et al. [2] have presented data which indicated the existence of four stages of stress-strain behavior during tensile testing of copper-tungsten composites. These stages were: elastic deformation of both fiber and matrix (stage 1), elastic deformation of fiber and plastic deformation of matrix (stage 2), plastic deformation of both fiber and matrix (stage 3), and failure of fiber and matrix (stage 4). Weeton et al [3] indicated that the shape of the stress-strain curve, especially in stage 4, depended on the manner in which the fibers fractured.

Stress-extension curves for some of the specimens used in the present investigation are shown in figures 7 through 12. It is observable that the point of occurrence of each of the stages and the flatness of the curves are affected by such test conditions as the number of layers, volume percent and diameter of the wires as well as the annealing temperature and wire misalinement. During stages 1 and 2 (region from zero stress to the yield point) the slopes of some of the curves are only slightly affected by annealing at $300{ }^{\circ} \mathrm{C}$ (figs. 7, 8, 10 , and 11). However, during the third stage (the region between yield and maximum load), the shape of 


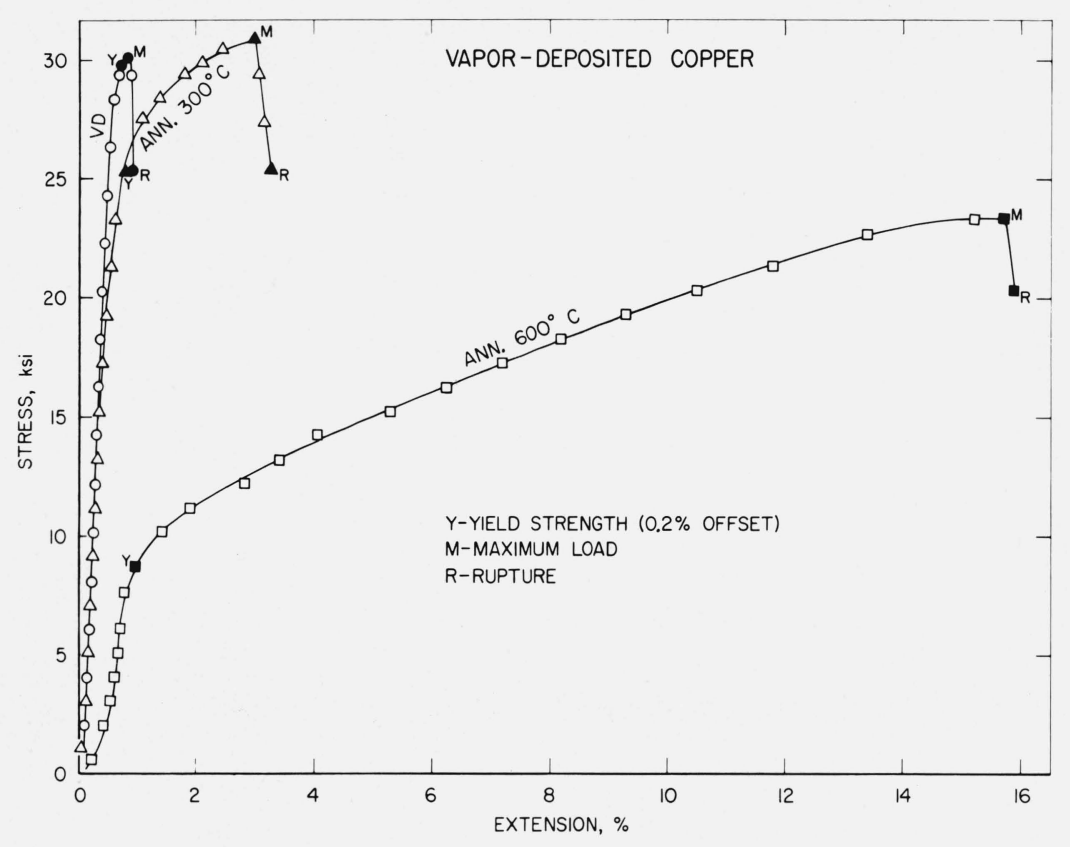

FigurE 5. Effect of annealing temperature on stress-extension curves of vapor-deposited copper specimens.

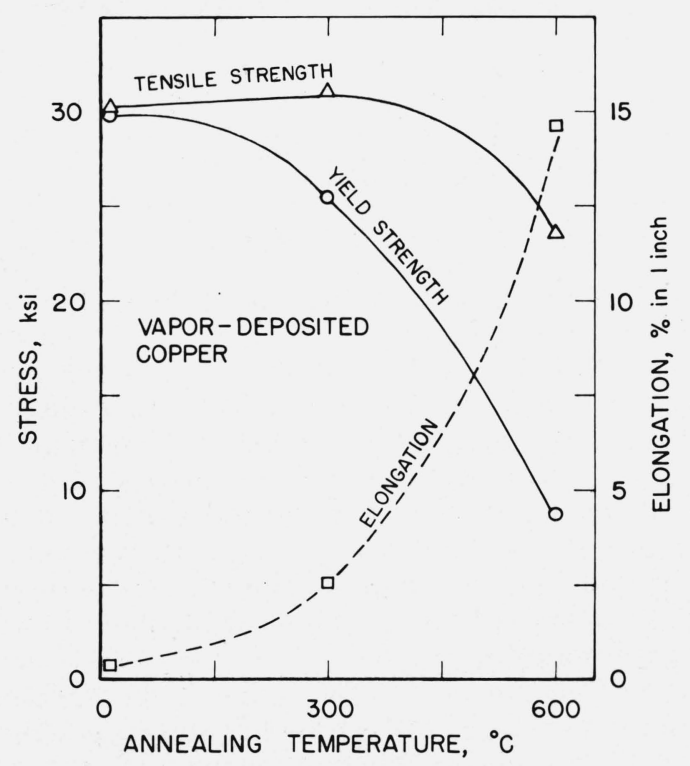

FigURE 6. Effect of annealing temperature on some tensile properties of vapor-deposited copper.

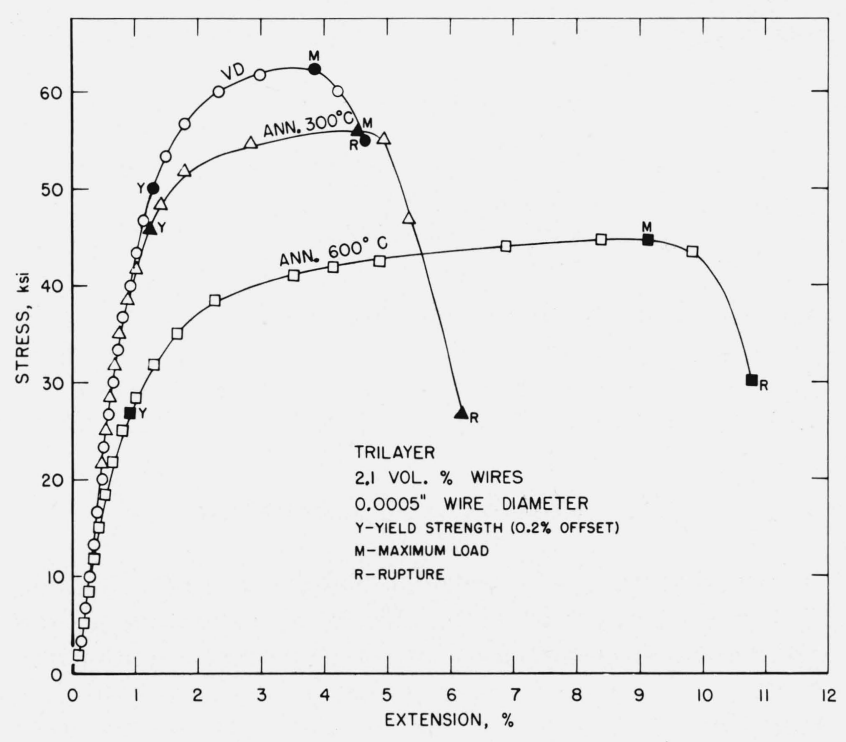

FIGURE 7. Effect of annealing temperature on stress-extension curves of vapor-deposited copper specimens containing 2.1 volume percent tungsten wires. 


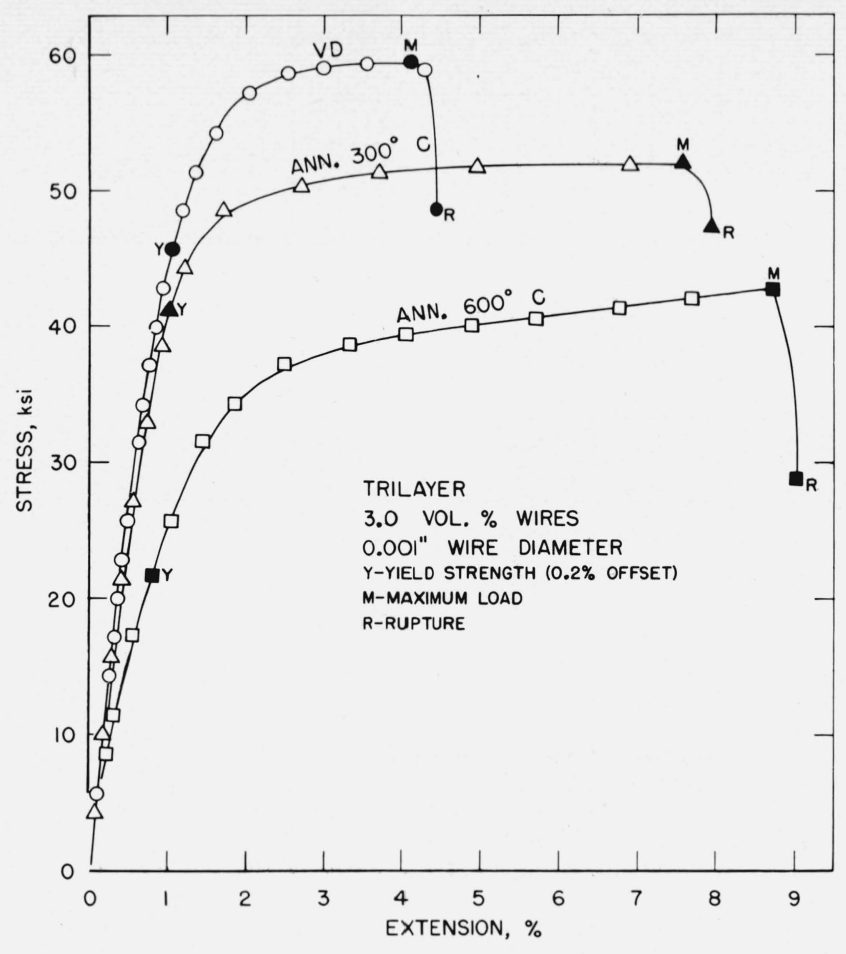

FIGURE 8. Effect of annealing temperature on stress-extension curves of vapor-deposited copper specimens containing 3 volume percent tungsten wires.

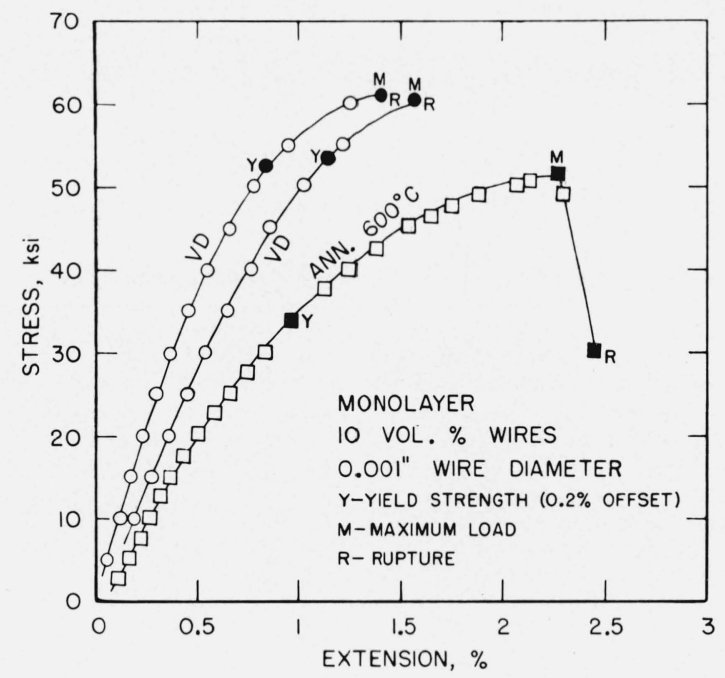

FigURE 9. Effect of annealing temperature on stress-extension curves of vapor-deposited copper specimens containing 10 volume percent misalined tungsten wires.

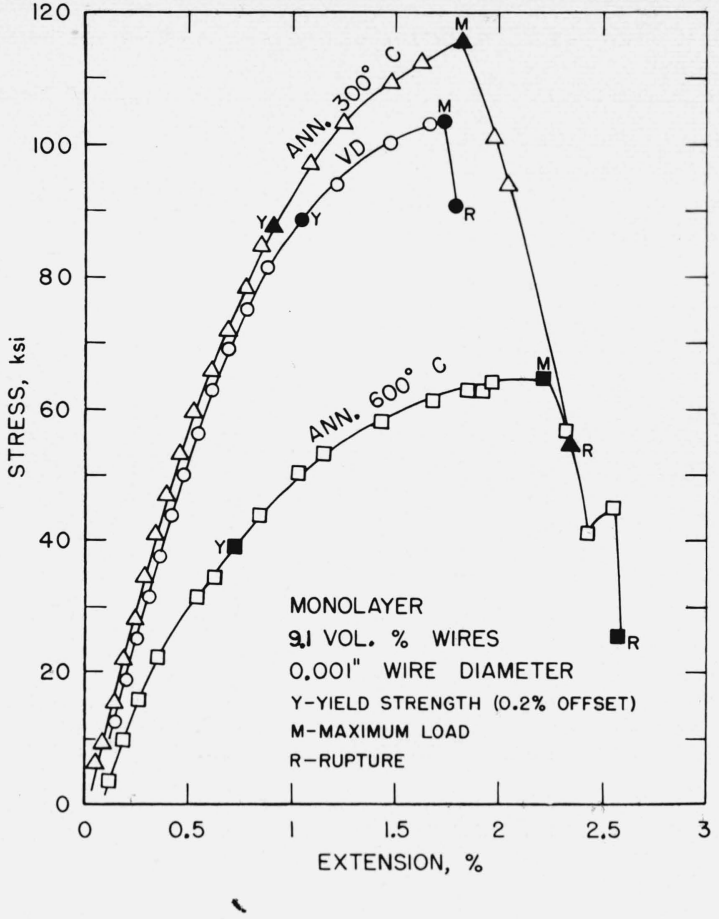

FIGURE 10. Effect of annealing temperature on stress-extension curves of vapor-deposited copper specimens containing 9.1 volume percent tungsten wires.

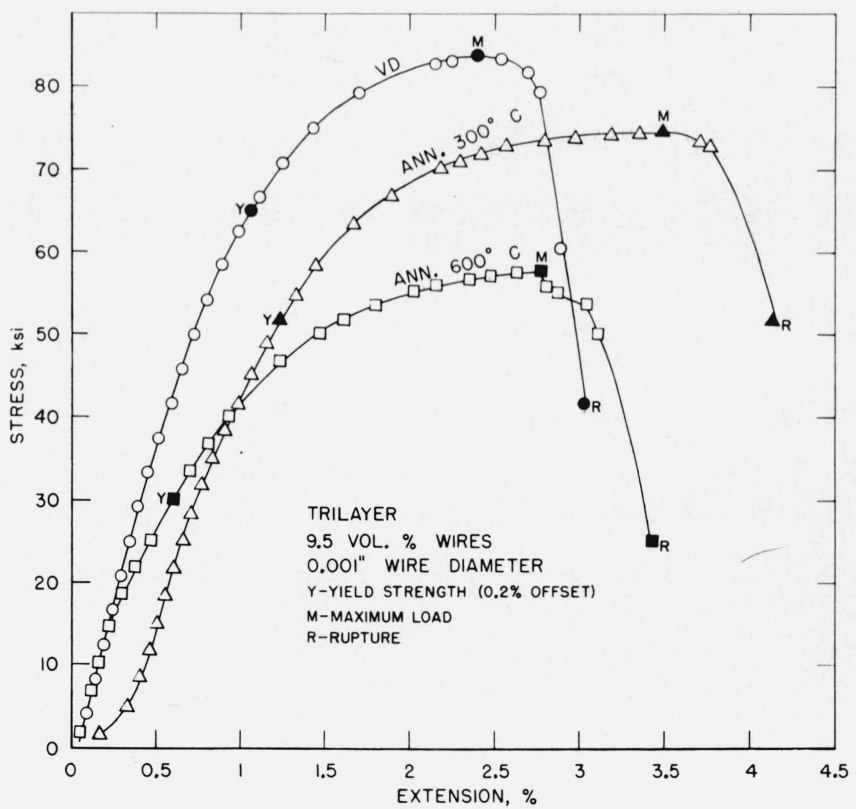

FigURE 11. Effect of annealing temperature on stress-extension curves of vapor-deposited copper specimens containing 9.5 volume percent tungsten wires. 
TABLE 1. Test conditions and results of room temperature tensile tests made on composites having a copper matrix with continuous tungsten wires

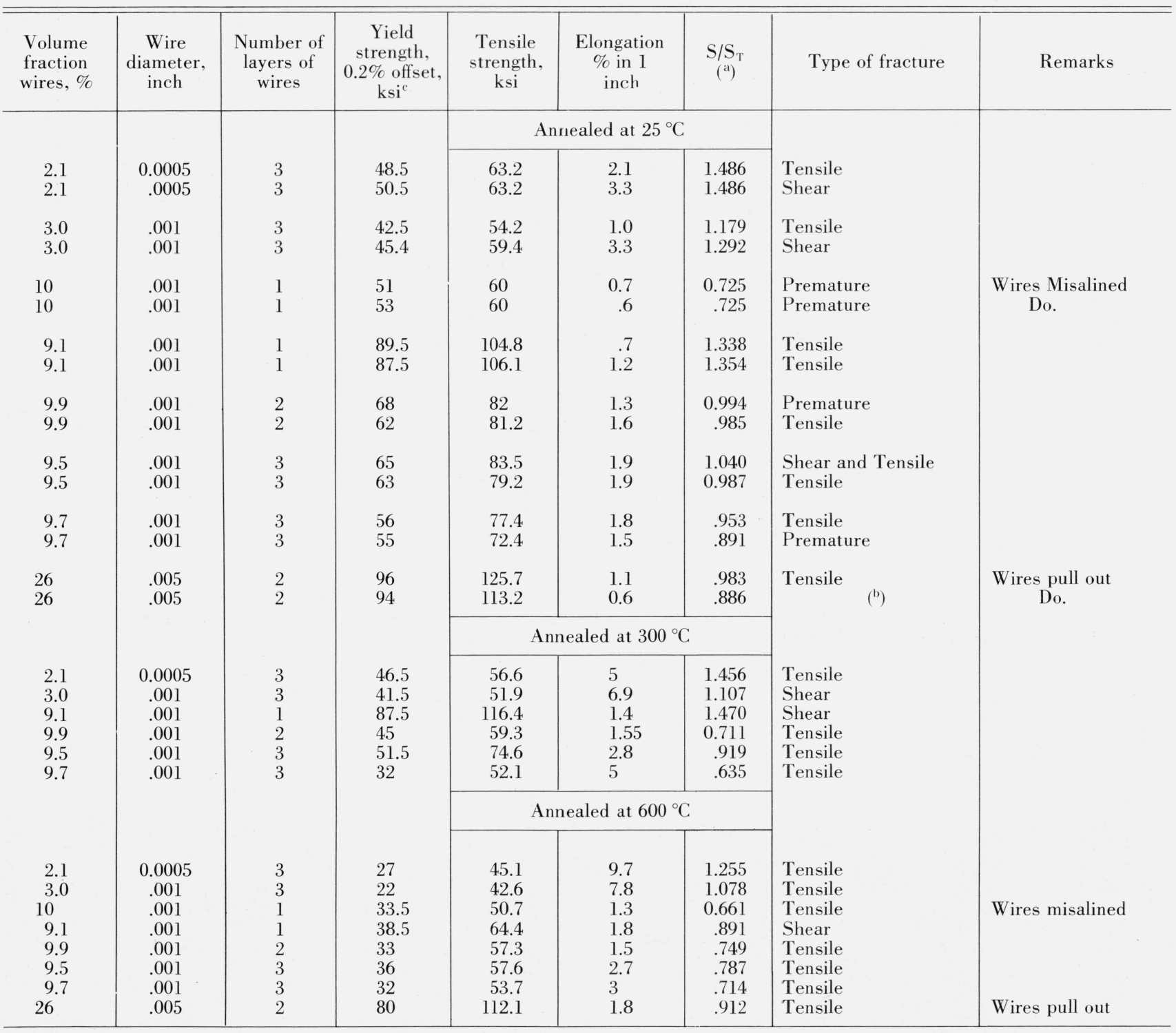

a $S / S_{T}=$ Tensile strength divided by theoretical tensile strength.

${ }^{\mathrm{b}}$ Fracture initiated outside of gage length.

${ }^{c} 1 \mathrm{ksi}=6.895 \mathrm{MN} / \mathrm{m}^{2}$. 
all the curves are affected by prior annealing. During the fourth stage (region between maximum load and rupture), a number of different rupture mechanisms appeared to occur, and they were strongly dependent on test conditions. For example, smooth curves in this region indicated that the wires retained some of thei bond strength after fracturing and acted as discontinuous fibers would be expected to act (fig. 7). As the volume percent or size of the wires increased (e.g. figs. 8 and 12), the stress-extension behavior indicated that nearly all the fibers fractured in the region of maximum load since very little extension occurred between maximum load and fracture. Misalinement of the fibers contributed to premature rupture. ${ }^{2}$ This behavior was observed with duplicate vapor-deposited specimens (VD curves, fig. 9) in which the wires were deliberately misalined. Catastrophic failure was not observed for the specimen with poorly alined wires and annealed at $600{ }^{\circ} \mathrm{C}$ (fig. 9). A strengthening effect occured during some portions of the fourth stage as shown by a reversal in the $600{ }^{\circ} \mathrm{C}$ curve in figure 10 ; whereas, some other specimens exhibited a discontinuous weakening effect during this stage $\left(600{ }^{\circ} \mathrm{C}\right.$ curve in fig. 11). Duplicate tests indicated slight differences in slope of the stress-extension curves in the first stage (VD curves, fig. 9) even though the tensile strength of the specimens from the same sheet was the same (table 1).

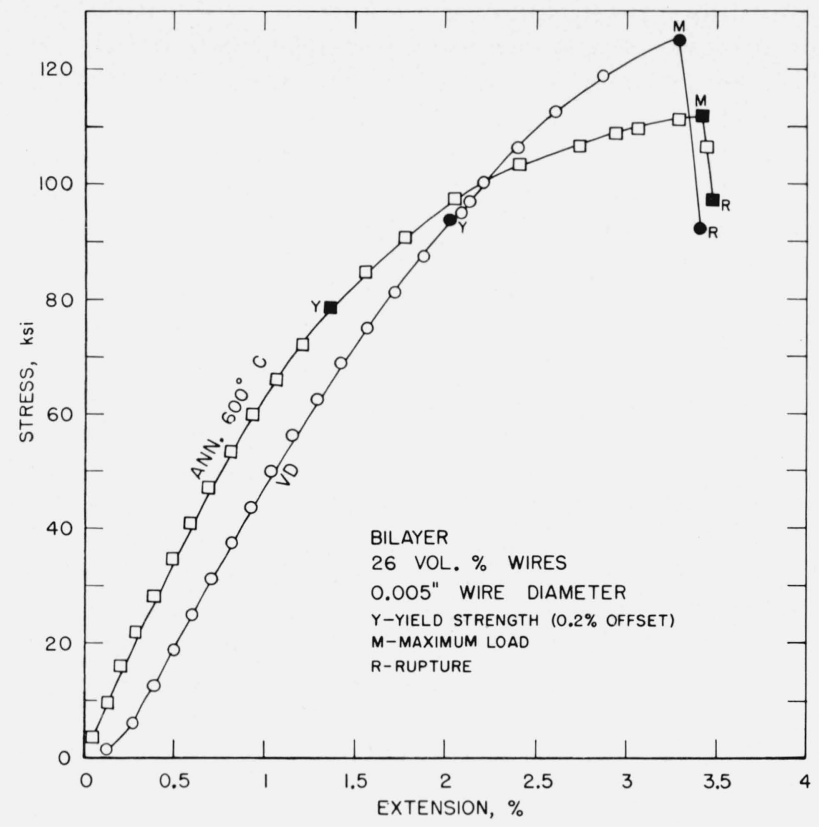

FIGURE 12. Effect of annealing temperature on stress-extension curves of vapor-deposited copper specimens containing 26 volume percent tungsten wires.

${ }^{2}$ Premature rupture indicates that the specimen fractured completely prior to the attainment of tensile strength.
Previous investigations $[1,3,5]$ have shown that a number of factors influence the strength and ductility of composites. The influence of test conditions on yield and tensile strength and elongation for composite specimens used in the present investigation is shown in figures 13, 14, and 15 and in table 1 . As indicated in

TABLE 2. Test conditions and results of tensile tests made on the vapor-deposited copper matrix material

\begin{tabular}{c|c|c|c}
\hline \hline $\begin{array}{c}\text { Annealing } \\
\text { temperature }\end{array}$ & $\begin{array}{c}\text { Yield } \\
\text { strength, } \\
0.2 \% \text { offset }\end{array}$ & $\begin{array}{c}\text { Tensile } \\
\text { strength }\end{array}$ & Elongation \\
\hline${ }^{\circ} \mathrm{C}$ & kisi & kisi & \% in l inch \\
25 & 30.2 & 30.3 & 0.36 \\
25 & 29.1 & 30.2 & .35 \\
300 & 25.5 & 31.1 & 2.5 \\
600 & 8.8 & 23.5 & 14.6 \\
\hline
\end{tabular}

figures $13 \mathrm{~A}$ and $14 \mathrm{~A}$, a decrease in the tungsten wire diameter from 0.001 to 0.0005 in resulted in an increase in the yield and tensile strength of the composite. This observation was consistent with the fact that the tensile strength of the smaller wire was 12 percent higher than that of the larger wire. This was not unexpected as the larger wire probably had more internal defects than the smaller one.

McDanels et al. [2] have discussed the effects of orientation of fibers on mechanical properties and concluded that composites with randomly oriented fibers should have lower strengths than similar composites in which the fibers (wires) were alined in the direction parallel to the direction of loading. This conclusion was confirmed by the data obtained in the present investigation as shown in figures $13 \mathrm{~B}$ and 14B. However, strengthening effects due to alining were less pronounced as the annealing temperatures were increased.

As shown in figures $13 \mathrm{C}$ and $14 \mathrm{C}$, sheet specimens with one layer of wires had higher strength than those with two or three layers of wires. This effect was less evident as the annealing temperature was raised to $600{ }^{\circ} \mathrm{C}$. Increasing the number of layers of wires from two to three had little or no effect on the yield and tensile strength. Moreover, increasing the annealing temperature for the monolayer from 25 to $300{ }^{\circ} \mathrm{C}$ had no effect on the yield strength (fig. 13C) and a slight increase tensile strength was observed (fig. 14C).

Jeck and Signorelli [4] suggested that decreasing the thickness of the matrix between fibers increases the shear strength of the matrix. As shown in figures 13D and $14 \mathrm{D}$, decreasing the thickness of matrix material $\mathrm{Cu}$ ) between the tungsten wires increased the yield and tensile strengths of the composites. The data indicate that a triaxial strengthening effect exists even for the annealed material.

The greatest increase in strength above that of the vapor-deposited copper was obtained with the composite specimens having 26 volume percent of 0.005 -in diam wires. These specimens also showed the least tendency to lose strength on increasing the annealing temperature from 25 to $600{ }^{\circ} \mathrm{C}$. This latter observation 


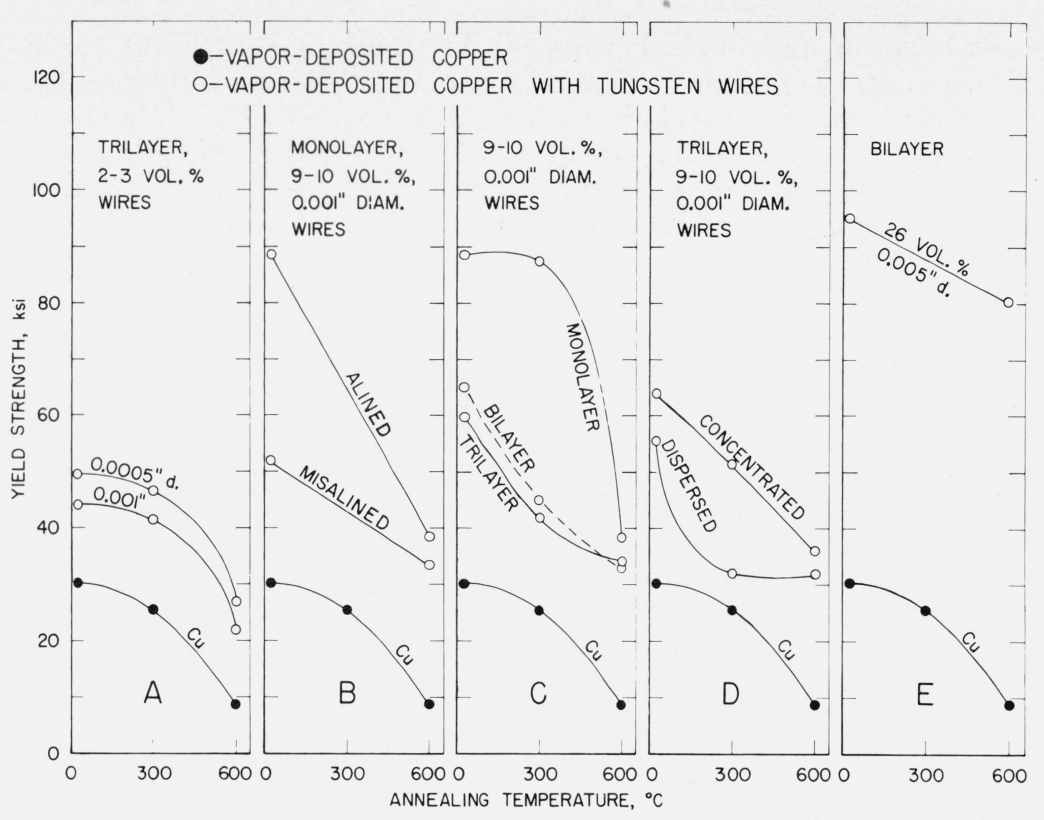

FIGURE 13. Effect of annealing temperature on the yield strength of vapor-deposited copper specimens and vapor-deposited copper specimens containing tungsten wires.

is due to the fact that this composite contained the least amount of matrix material. Moreover, the strengthening occurred in spite of a 36 percent decrease in tensile strength of the 0.005 -in diam wires below that of the 0.0005 -in diam wires.

The influence of test conditions on elongation of the specimens used in the present investigation is shown in figure 15. Elongation of all the composites was greater than that of the copper for the specimens annealed at $25^{\circ} \mathrm{C}$; whereas the reverse was true for those annealed at $600{ }^{\circ} \mathrm{C}$. With few exceptions elongation increased with an increase in annealing temperature, a decrease in volume percent wires, better wire alinement, an increase in number of layers of wires, and interwire distance. Due to the scarcity of data no conclusions could be drawn concerning the effects of wire diameter on elongation.

The law of mixtures, in which the strength of a composite is said to be equal to the sum of the tensile strength of each component multiplied by its volume fraction, has been shown to be valid for a number of composites. However, deviations from the law have been found for some complete systems and at various volume fractions of wires for the same system. Weeton and Signorelli [3] summarized a number of factors known to produce synergistic effects in a composite. Conversely, deleterious effects may be attributed to the fact that matrix and fibers (wires) may not necessarily behave in the same manner individually as they do collectively in a composite. Both synergistic and deleterious effects were observed in the present investigation (fig. 16). Strengths above those calculated from the law of mixtures were observed at low wire content while the opposite was observed for the high volume percent wire content. Tensile strength-theo- retical tensile strength ratios associated with both the deleterious and synergistic effects were lowered by raising the annealing temperature to $600^{\circ} \mathrm{C}$.

Properties other than strength and ductility may be important in engineering design of structural components. Electrical conductivity and resistivity are two of these properties. Using $\mathrm{Cu}-\mathrm{W}$ composites made by liquid infiltration, McDanels [6] indicated that electrical conductivity was a linear function of fiber content. The relationship showing changes in electrical resistivity and conductivity of the present composites and the strength and volume percent of tungsten wires is shown in figures 17 and 18. An initial rapid rate of increase in electrical resistivity with increase in volume percent of wires or tensile strength was followed by a slower increase as these variables were increased (fig. 17A and B). As shown in figure 17C, no consistent relations existed between electrical resistivity and the tensile strength-theoretical tensile strength ratio. The decrease in electrical conductivity with increase in strength is shown in figure 18. All of these curves show inflection points after which the rate of decrease in electrical conductivity with increase in strength decreases as the yield or tensile strength increases. The curves appear to level off at about 65 percent decrease in electrical conductivity below that of the vapordeposited copper.

\section{Metallography}

Some of the copper and $\mathrm{Cu}-\mathrm{W}$ composite specimens were examined after rupture. The results are shown in figures 19 through 22. Rupture of the copper specimens, with no wires, initiated at one edge and progressed through the specimen to the opposite edge of 


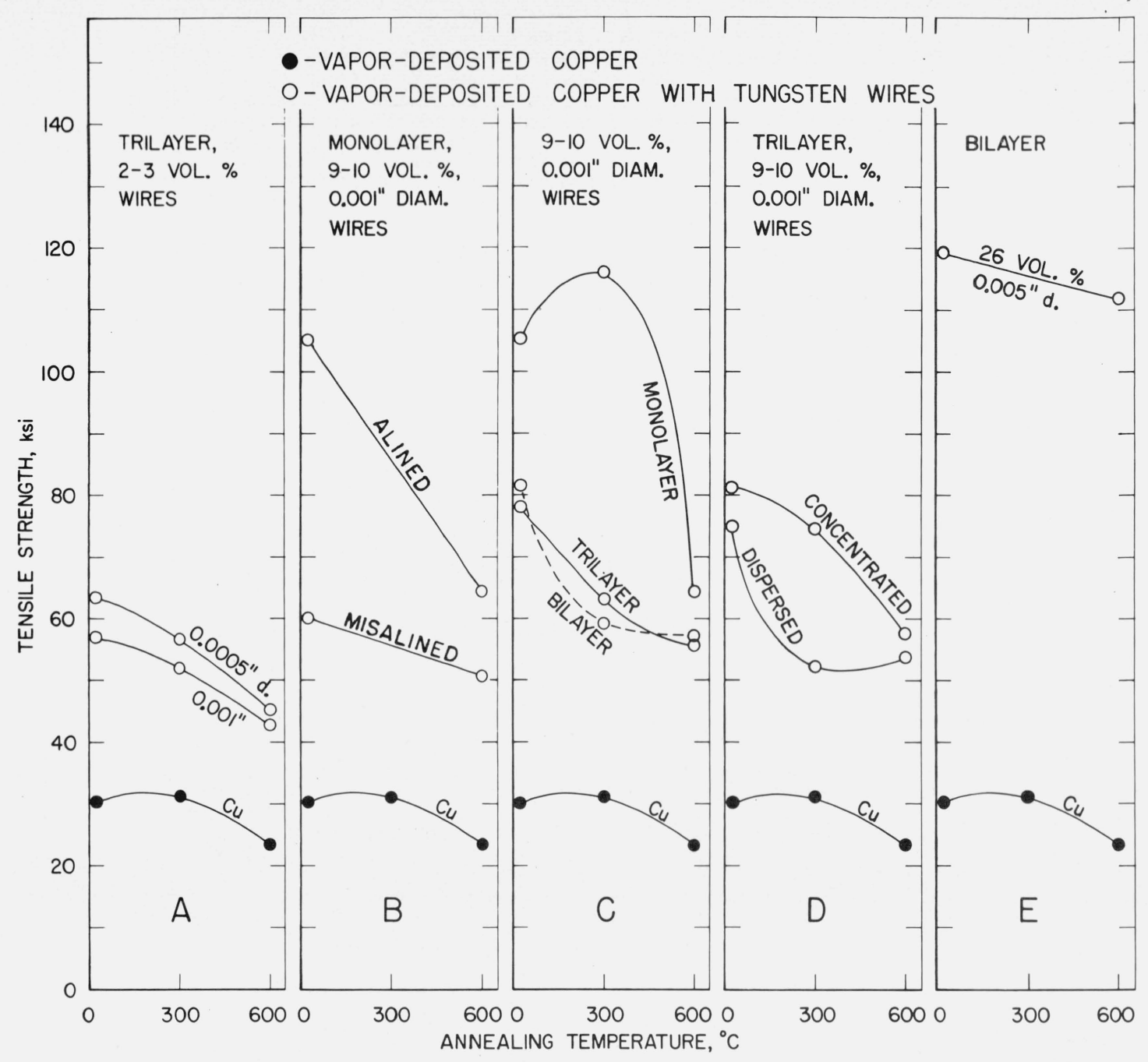

Figure 14. Effect of annealing temperature on the tensile strength of vapor-deposited copper specimens and vapor-deposited copper specimens containing tungsten wires.

the specimen (fig. 19B). The rate at which the fractures progressed decreased with increase in annealing temperature. Each of the fractures, shown in figure 19 , was classified as tensile in that they occurred after the attainment of maximum load (fig. 5) and did not exhibit shear-type characteristics for which the stressextension curves would be similar. The fracture surface became more jagged as the annealing temperature increased (fig. 19). This tendency was accompanied by an increase in the number of surface cracks that did not link up to become a part of the complete fracture.

In table 1 and figure 20, the types of fractures of the composites are classified as premature, tensile, and shear. Premature fractures were associated with those specimens which ruptured before the attainment of the normal maximum load as indicated by stressextension curves, such as the VD curves shown in figure 9. No premature fractures were observed for specimens annealed at 300 or $600{ }^{\circ} \mathrm{C}$. Moreover, where comparisons were possible, prematurity was accompanied by low ductility (table 1 and fig. $20 \mathrm{~A}$ and B). As indicated in table 2 and illustrated in figure 20C, most of the composite specimens exhibited a tensile-type fracture. From the amount of data available, ductility values associated with tensile fractures appeared to fall between the low values for the premature and the high values for the shear-type fractures. A typical shear-type fracture is shown in figure 20D, while a part shear-part tensile fracture is shown in figure $20 \mathrm{E}$. Even though the fracture of the latter specimen occurred outside the gage length and was accompanied by some wire-pullout, none of these factors affected either the tensile strength or elongation, as shown by a comparison with the data obtained on a duplicate specimen that fractured in a tensile manner (table 1). However, when extreme wire pull-out was observed during the tests (fig. 20F), no useful data could be obtained and the test results had to be discarded. 


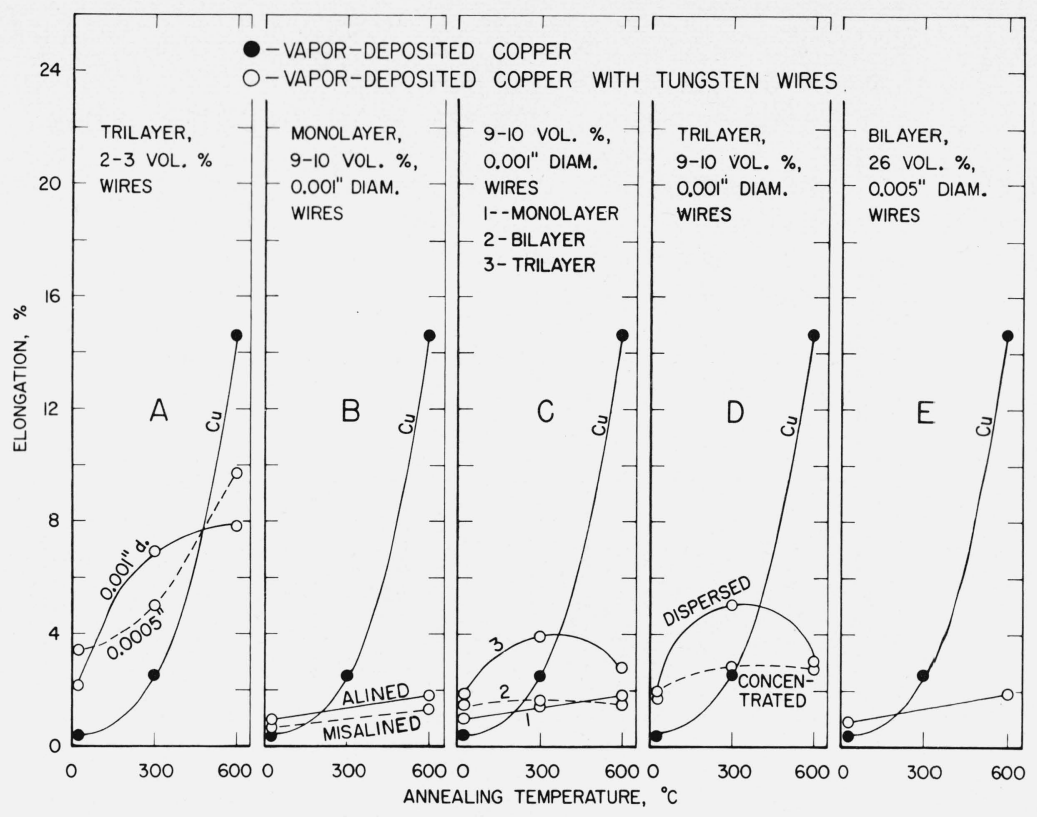

FigURE 15. Effect of annealing temperature on elongation values of vapor-deposited copper specimens and vapor-deposited copper specimens containing tungsten wires.

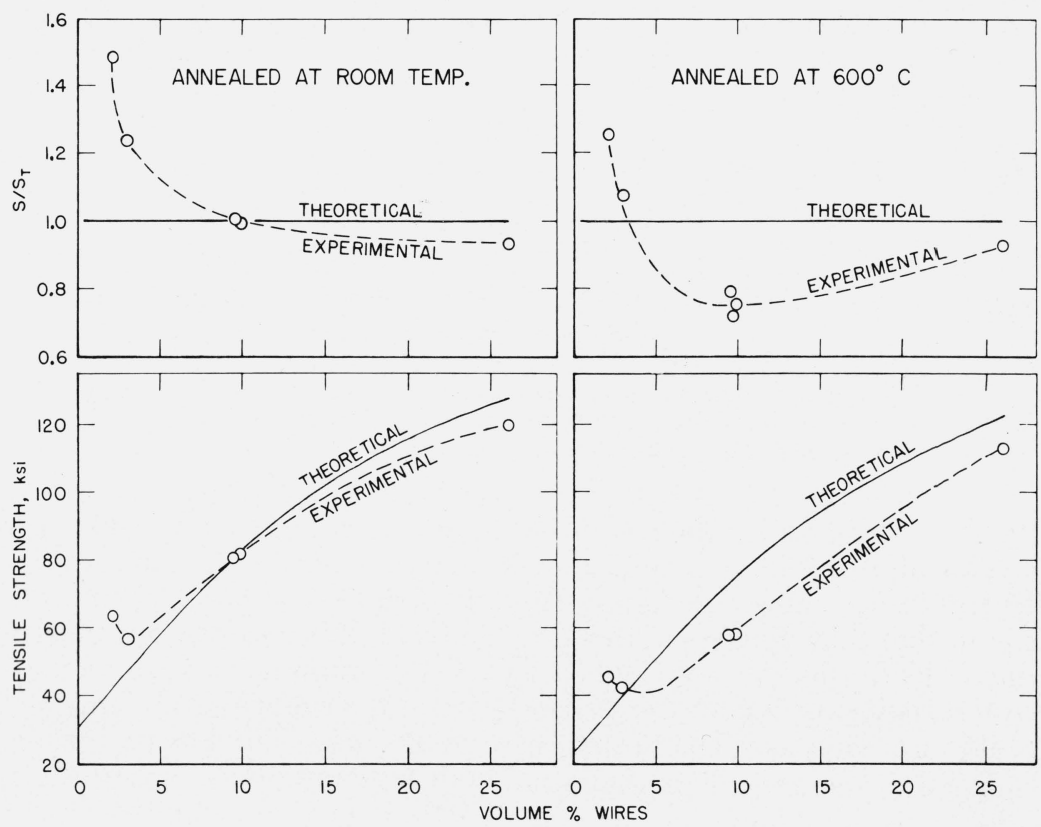

Figure 16. Effect of volume percent tungsten wires on tensile strength of $\mathrm{Cu}-\mathrm{W}$ composite specimens and on the ratio of the tensile strength $(\mathrm{S})$ to the theoretical tensile strength $\left(\mathrm{S}_{\mathrm{T}}\right)$ based on the law of mixtures. 


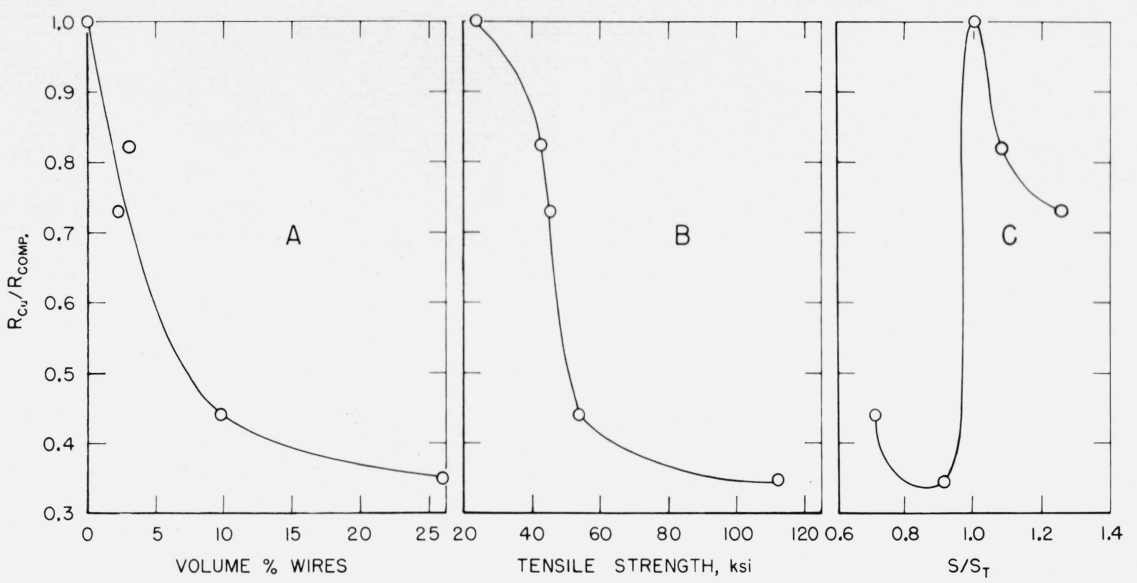

FigurE 17. Effect of volume percent tungsten wires, tensile strength and the tensile strength-theoretical tensile strength ratio on the electrical resistivity of $\mathrm{Cu}-\mathrm{W}$ composites. $\mathrm{R}_{\mathrm{Cu}^{\prime}}$ Resistivity of the vapor-deposited copper. $\mathrm{R}_{\text {Comp' }}$ Resistivity of the $\mathrm{Cu}-\mathrm{W}$ composites.
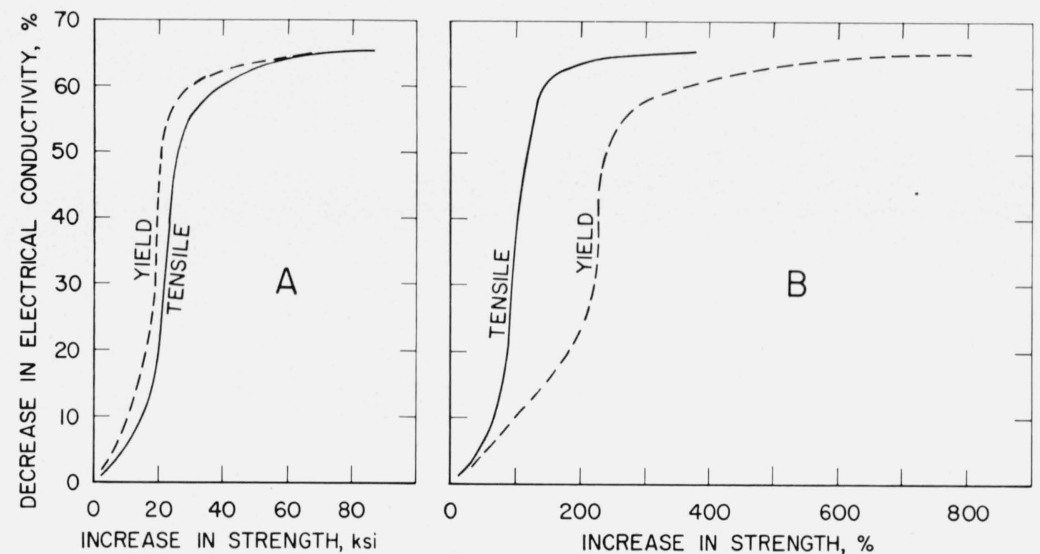

FIGURE 18. Relationship between strength and electrical conductivity of $\mathrm{Cu}-\mathrm{W}$ composites. 


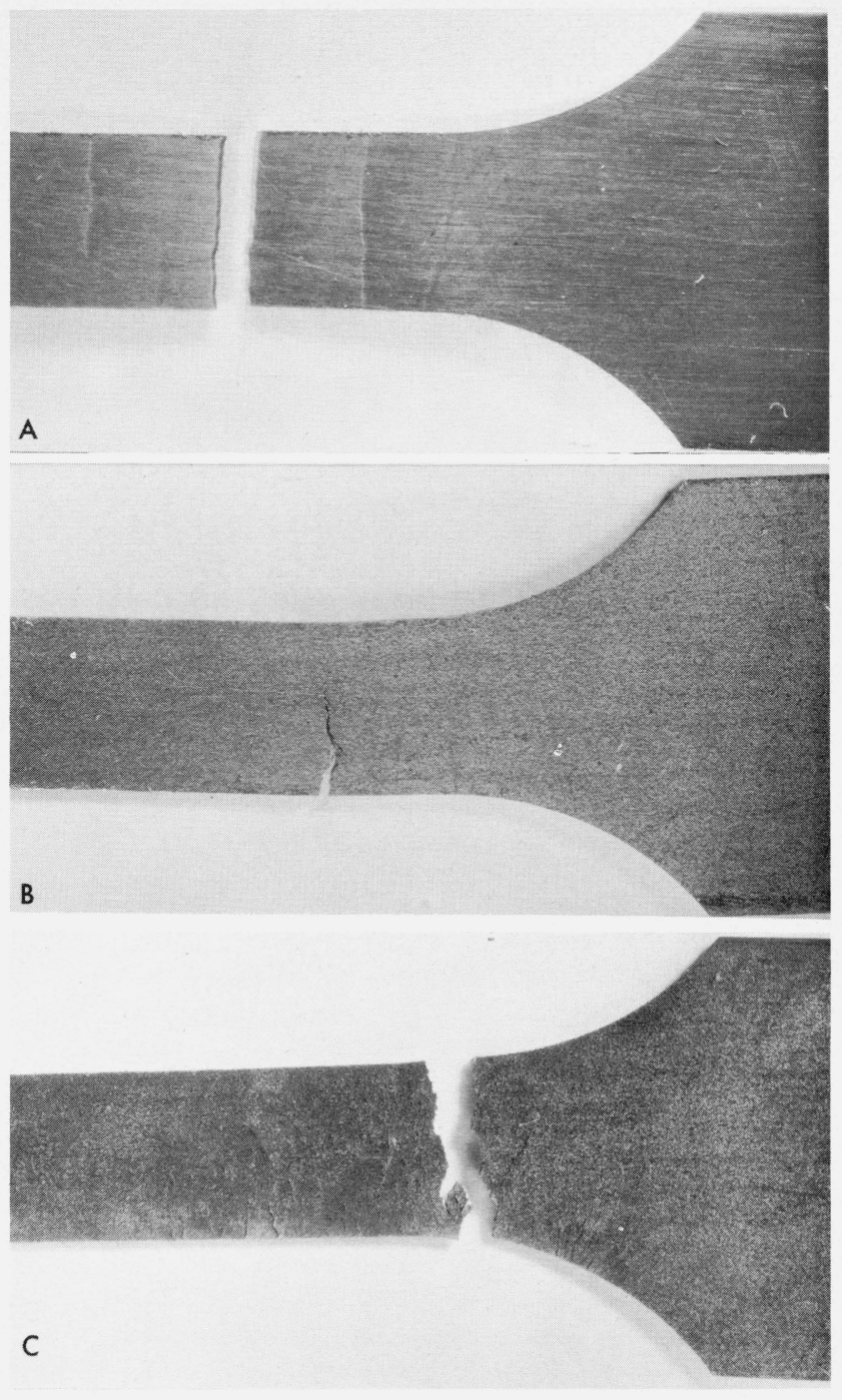

FIGURE 19. Vapor-deposited copper specimens after fracture. $\times 3^{1 / 3}$

A. Annealed at $25^{\circ} \mathrm{C}$
B. Annealed at $300^{\circ} \mathrm{C}$

C. Annealed at $600^{\circ} \mathrm{C}$

FIGURE 20. Vapor-deposited copper specimens containing tungsten wires, after fracture. $\times 5$

(Data obtained on $\mathrm{F}$ not used in this investigation.)
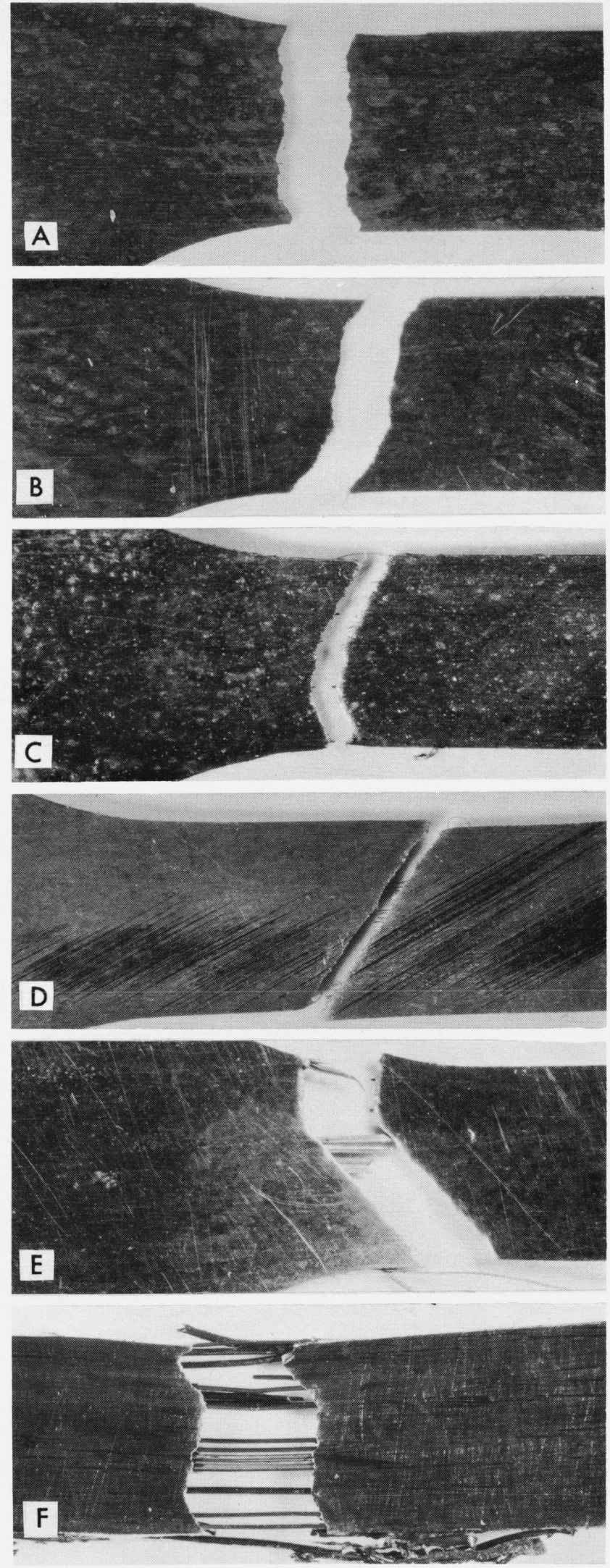

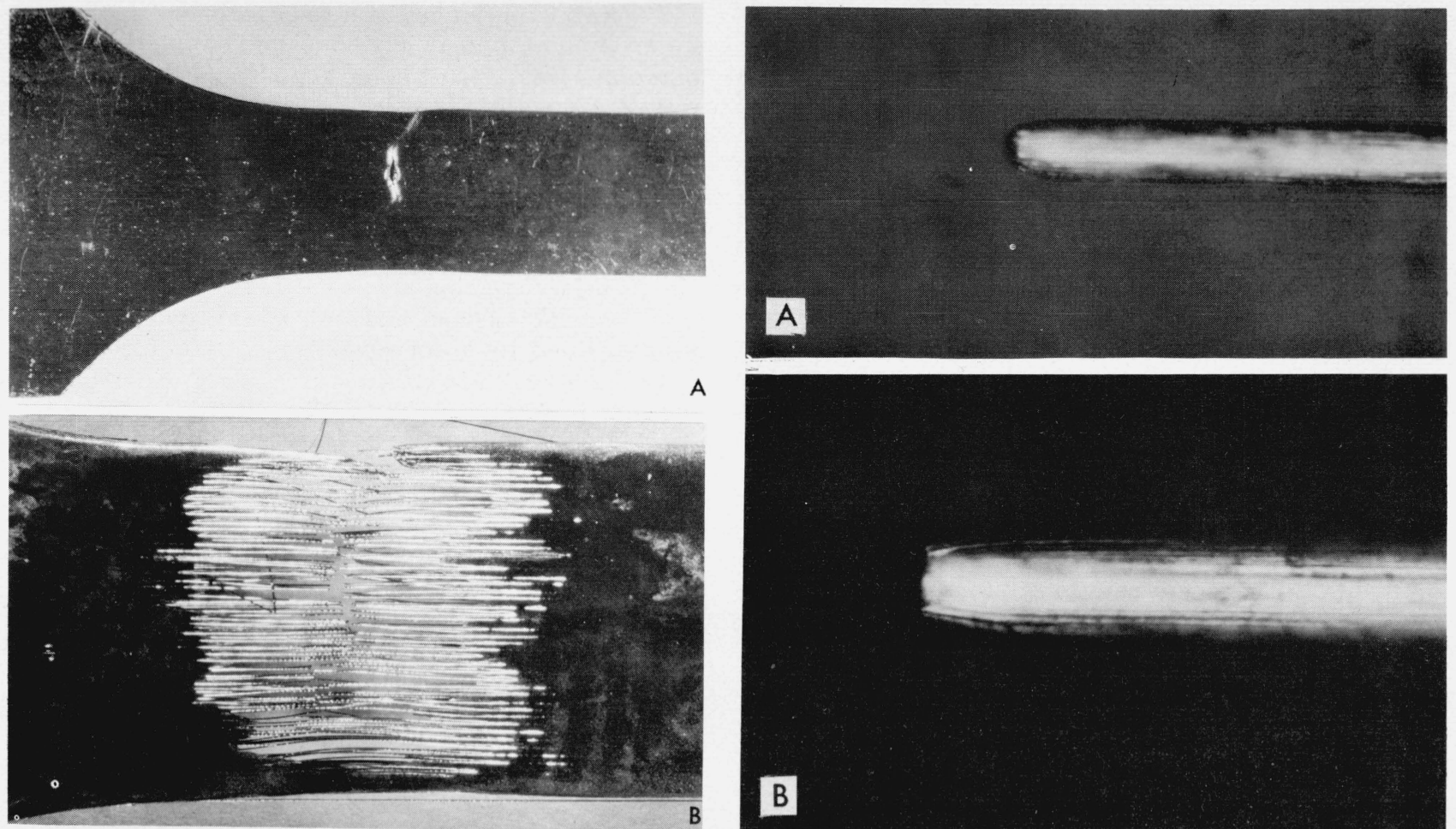

A
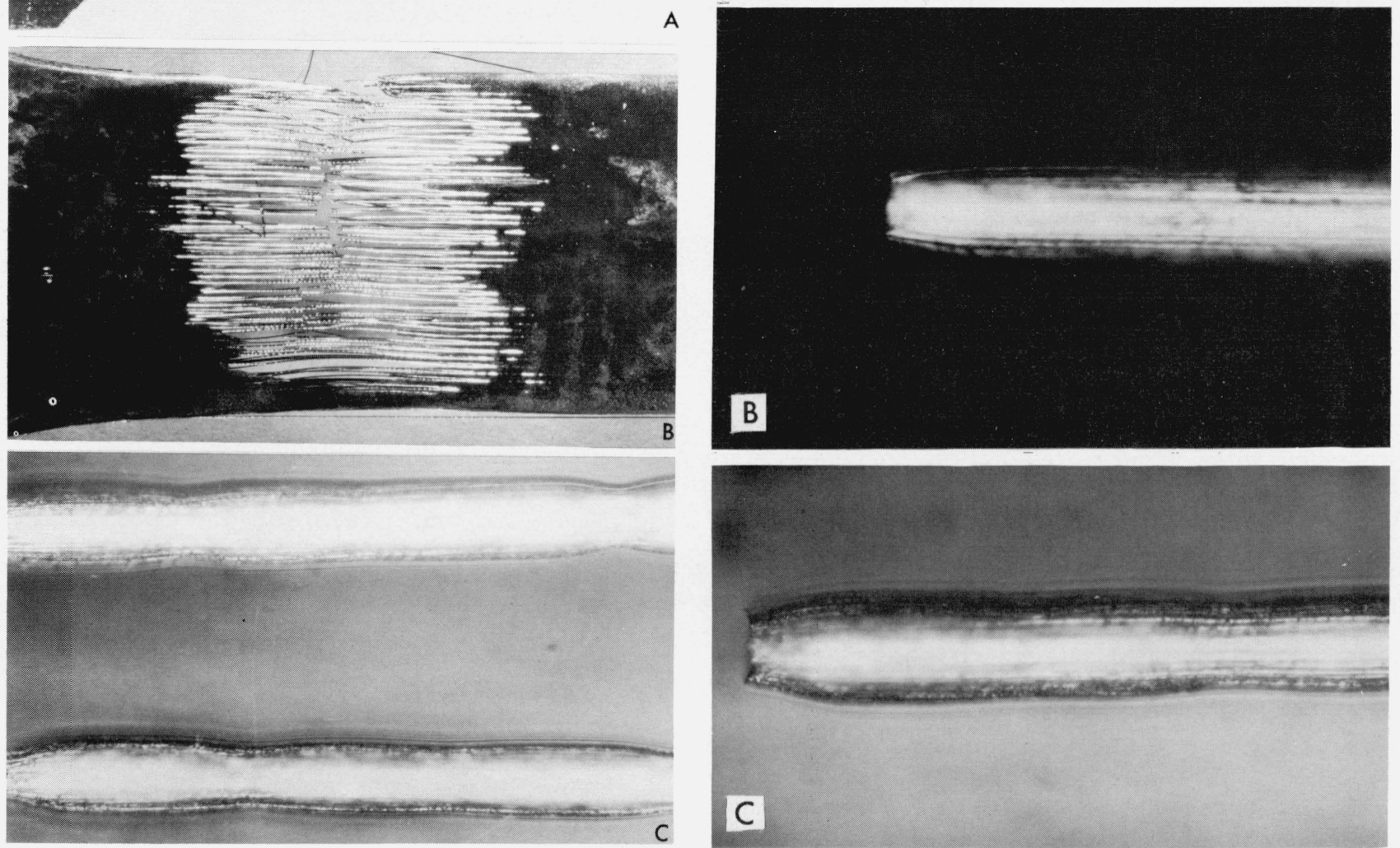

FIGURE 21. Vapor-deposited copper specimen containing 9.5 volume percent tungsten wires.

Test stopped before complete fracture.

A. Surface showing region of initiation of fracture. $\times 3.3$

B. Same region as A, after dissolution of some of the copper by $\mathrm{HNO}_{3}$ (conc.). $\times 6.6$

C. A deformed and a fractured tungsten wire from area shown in B. $\times 330$

FigURE 22. Fractured tungsten wires from $\mathrm{Cu}-\mathrm{W}$

composite specimens after complete fracture in tension.

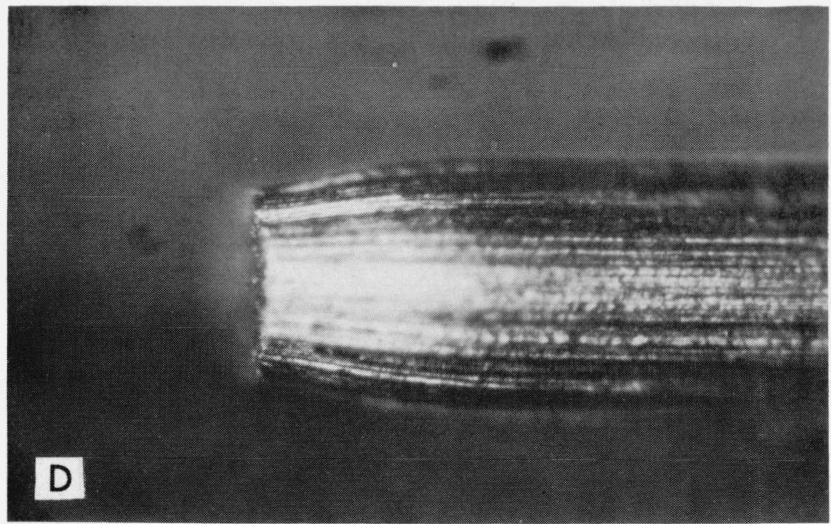


Fracture of most of the composite specimens was initiated away from the edges of the specimens as illustrated in figure 21A for a specimen for which the test was stopped after the attainment of maximum load and before complete rupture. After the copper was dissolved away by nitric acid, the tungsten wires were exposed in the region of the crack (fig. 21B). Some of the wires had ruptured and some had been deformed and remained intact. Although the fractures occurred after extensive localized deformation ("necking"), a number of necks occurred in regions away from complete fracture (fig. 21C). Figure 22 indicates that the mechanisms of deformation and fracture of the tungsten wires imbedded in the copper matrix were essentially the same for all sizes of the wires used in this investigation.

The authors are deeply grateful to Glenn W. Geil for his helpful discussions and to Mrs. Gertrude M. Davis for her assistance in the preparation of this manuscript.

\section{Summary}

1. Short-time tensile tests were made at room temperature on vapor-deposited copper specimens containing zero to 26 volume percent of continuous tungsten wires. Prior to testing, the specimens were annealed at 25,300 , or $600{ }^{\circ} \mathrm{C}$.

2. A decrease in strength, due to an increase in annealing temperature, was generally accompanied by an increase in ductility.

3. An increase in strength was attributed to an increase in volume fraction of tungsten wires, decrease in wire diameter or decrease in the number of layers of wires.

4. Specimens having poorly alined wires tended to have lower strength and ductility than specimens in which the wires were alined.

5. Specimens having wires close together tended to have higher strength and lower ductility than those with wires more widely dispersed.

6. The shape of the stress-strain curves and the types of fractures obtained were influenced by all the variables considered.
7. Based on the law of mixtures the strength values for specimens annealed at $25^{\circ} \mathrm{C}$ and having $2-3$ volume percent wires were higher than the calculated theoretical strengths. For the 9-10 volume percent wire composites they were equal to the theoretically calculated values and for the 26 volume percent they were lower than the theoretical values.

8. Additional deviations from the law of mixtures were caused by annealing the specimens at 300 or $600{ }^{\circ} \mathrm{C}$ prior to testing.

9. An increase in strength of the composites was accompanied by a decrease in electrical conductivity.

10. Three types of fractures were observed: premature, tensile, and shear. Premature fractures were associated with specimens less ductile and shear fractures with specimens more ductile than those that fractured in a tensile manner.

11. Fracture of the vapor-deposited copper initiated near one edge of the specimen; whereas fracture initiated near the center portion of the composite specimens.

12. Tungsten wires in the composites failed after considerable necking of the wires.

13. The number of "necks" in the individual wires appeared to be a function of wire diameter.

14. The tungsten wires appeared to have a spread in fracture strengths and the composite failure resulted from complete fracture of all the wires.

\section{References}

[1] Kelly, A., and Davies, G. J., The principles of the fibre reinforcement of metals, Met. Rev. 10, No. 37, 1-78 (1965).

[2] McDanels, D. L., Jeck, R. W., and Weeton, J. W., Stress-strain behavior of tungsten-fiber-reinforced copper composites, NASA TN D-1881 (1963).

[3] Weeton, J. W., and Signorelli, R. A., Fiber-metal-composite materials, NASA TN D-3530 (1966).

[4] Jeck, R. W., and Signorelli, R. A., The effect of interfiber distance and temperature on the critical aspect ratio in composites, NASA TN D-4548 (1968).

[5] Cooper, G. A., Electroformed composite materials, Journal of Matls. Sci. 2, 409 (1967).

[6] McDanels, D. L., Electrical resistivity and conductivity of tungsten-fiber-reinforced copper composites, NASA TN D-3590 (1966).

(Paper 74C3\&4-303) 